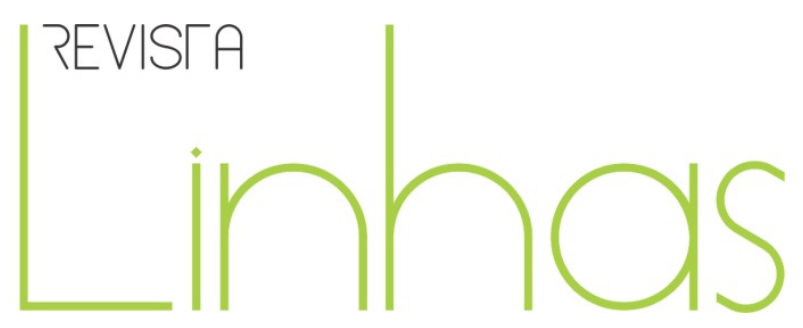

\title{
Novos alunos e apropriações heréticas da Universidade na França ${ }^{1}$
}

\begin{abstract}
Resumo
Interessando-nos no ingresso no primeiro ciclo universitário francês de estudantes de primeira geração (isto é, aqueles cujos pais não fizeram estudos superiores), originários dos bacharelados tecnológicos e profissionais dos liceus, desejamos mostrar aqui a pertinência da análise do "jogo universitário" tal como propuseram Pierre Bourdieu e Jean-Claude Passeron em 1964 em Os herdeiros. Na verdade, as chances de acesso, de permanência e de sucesso na Universidade não se reduzem à posse de competências de ordem unicamente escolar, mas remetem de maneira mais ampla à posse de um capital cultural específico. Parece assim que o fracasso no primeiro ciclo universitário não tem bases escolares (domínio dos saberes fundamentais), mas implica igualmente, e por vezes essencialmente, desajustamentos de ordem propriamente social (comportamento inoportuno, atitude deslocada, etc.) que podem provocar humilhações diversas e, finalmente, uma estigmatização da parte dos atores da orientação escolar, dos professores e dos outros estudantes.
\end{abstract}

Palavras-chave: Estudantes; Universidade; Diplomas profissionais; Fracasso; Capital cultural.

\author{
Romuald Bodin \\ Doutor em Ciências Sociais pela \\ École des Hautes Études en \\ Sciences Sociales - EHESS - \\ Paris/França \\ romuald.bodin@univ-poitiers.fr
}

\section{Sophie Orange}

Doutora pela Université de Poitiers - França

sophie.orange@univ-nantes.fr

\begin{abstract}
Para citar este artigo:
BODIN, Romuald; ORANGE, Sophie. Novos alunos e apropriações heréticas da Universidade na França. Revista Linhas. Florianópolis, v. 15, n. 29, p. 182-201, jul./dez. 2014. Título original: Nouveaux étudiants et appropriations hérétiques de l'Université en France. Traduzido por Fernando Coelho, com revisão técnica de Ione Ribeiro Valle.
\end{abstract}

DOI: $10.5965 / 1984723815292014182$

http://dx.doi.org/10.5965/1984723815292014182

\footnotetext{
${ }^{1}$ Traduzido por Fernando Coelho - zeffiretto@gmail.com, com revisão técnica de lone Ribeiro Valle ione.vale@ufsc.br.
} 


\title{
New students and heretical appropriation of university in
} France

\begin{abstract}
The aim of this article is to analyse first-generation students (i.e. whose parents never enrolled in postsecondary education) entering university in France with vocational high school graduations. Our objective is to evidence that the model of "university game", developed by Pierre Bourdieu and Jean-Claude Passeron in The inheritors (1964), is still relevant. Indeed, access and success chances at University are not only dependent from the possession of school skills, but are also linked to the possession of a specific cultural capital. In other words, dropout from the first universitary cycle cannot only be explained by school performances (knowledge of literacy skills) but is also due, sometimes mainly, to social disadjustment situations (disappropiate behaviour, out of place dispositions, etc.) entailing humiliations and finally a stigmatization process by guidance counselors, teachers and other students.
\end{abstract}

Keywords: Students; University; Vocational graduations; Dropout; Cultural capital. 


\section{Introdução}

$\mathrm{Na}$ França, o acesso ao ensino superior exige a obtenção do bacharelado², diploma de conclusão do ensino secundário oferecido nos liceus ${ }^{3}$. Primeiramente único, o bacharelado dito "geral" foi complementado ao longo da segunda metade do século XX por dois outros bacharelados: o "bacharelado tecnológico", criado em 1968, e em seguida o "bacharelado profissional”, criado em 1985. Esses dois diplomas, mais práticos e menos teóricos, eram destinados aos alunos que apresentavam um nível insuficiente para ingressar na via geral. Se essas três áreas acolhem alunos diversamente dotados escolarmente (dos mais dotados nas áreas gerais até os menos dotados nas áreas profissionais), elas também abarcam perfis sociais diferentes. O bacharelado geral é constituído por apenas 30\% de candidatos de origem popular (filhos de operários e de empregados), contra $45 \%$ para o bacharelado tecnológico e 55\% para o bacharelado profissional. Inversamente, os filhos de pais de níveis superiores estão desigualmente distribuídos nessas três áreas: 30\% na área geral, 15\% na área tecnológica e 7\% na área profissional. No momento de sua criação, os bacharelados tecnológicos e profissionais eram diplomas conclusivos, ou seja, destinavam seus diplomados ao ingresso no mercado do trabalho e não à continuidade dos estudos.

Nos anos 1980, a democratização do ensino secundário e superior despertou vocações em famílias que até então foram mantidas à margem. Os objetivos de chegar aos "80\% de uma faixa etária no bacharelado", lançado em 1985, e em seguida aos "50\% de diplomados no ensino superior nas novas gerações", inscrito na lei sobre a Escola em 2005, foram considerados como chamadas aos jovens que não necessariamente haviam vislumbrado acessar ao ensino superior. Em 2009, a reforma do bacharelado profissional, que reduziu sua duração de formação de 4 para 3 anos, se inscreve no mesmo projeto de ampliação do número de candidatos ao ensino superior. Mas, embora os bacharéis profissionais, assim como há muito tempo os bacharéis tecnólogos, estejam doravante mais sujeitos a incitações mais ou menos explícitas à continuidade dos estudos, eles são

\footnotetext{
2 Do original "baccalauréat", este diploma é conferido no final do Ensino Médio (ou ensino secundário), ministrado nos liceus, após a aprovação em um exame nacional que confere o título de bacharel. (N.T.)

${ }^{3}$ Ver o esquema simplificado do sistema escolar francês apresentado no Anexo 1.
} 
tolerados apenas na medida em que permanecem à margem do ensino superior, ou seja, em áreas não centrais ou menos valorizadas ${ }^{4}$, particularmente nos ciclos profissionalizantes curtos (Seção de técnico superior, Instituto universitário de tecnologia, Escolas de serviço social e de paramédicos). Eles são aceitos nas formações pós-bacharelado somente se souberem manter seu ranking escolar, ou seja, se se contentarem com formações curtas e profissionais ${ }^{5}$; enquanto os bacharéis de formação geral, público tradicional do ensino superior, podem estudar onde acharem melhor. $\mathrm{O}$ ingresso na Universidade, para esses estudantes "recém-vindos", para não dizer esses estudantes "novatos", é em compensação considerado como a expressão de uma pretensão despropositada. Esse acesso aos ciclos longos e generalistas do ensino superior é, aliás, objeto de controles no quadro dos procedimentos de orientação ativa, ao longo da qual o aluno do último ano do liceu é aconselhado (e dissuadido) tanto pelos seus professores quanto pelo estabelecimento de ensino sobre a pertinência de sua escolha de orientação.

Interessando-nos pelo ingresso no primeiro ciclo universitário de estudantes de primeira geração (ou seja, aqueles cujos pais não fizeram estudos superiores), oriundos de bacharelados tecnológicos e profissionais dos liceus, queremos mostrar aqui a pertinência da análise do "jogo universitário" tal como foi proposta por Pierre Bourdieu e Jean-Claude Passeron em 1964 em Os herdeiros ${ }^{6}$. Ver-se-á particularmente que as chances de acesso, de permanência e de sucesso na Universidade não se reduzem à posse de competências de ordem unicamente escolar, mas remetem de maneira mais ampla à posse de um capital cultural específico. Compreender-se-á portanto que os novos estudantes devam, para permanecer na Universidade, não somente responder a exigências escolares para as quais não foram bem preparados, devido ao seu curso anterior, mas também decodificar e em seguida integrar as regras e as expectativas implícitas desse jogo universitário (conjunto de saber ser, de saber fazer e de saber dizer),

\footnotetext{
${ }^{4}$ Anne-Marie Thiesse, « Des plaisirs indus. Pratiques populaires de l'écriture et de la lecture », Politix, $\mathrm{n}^{\circ} 13$, 1991, p. 57-67.

${ }^{5}$ A continuidade de estudos no final de um bacharelado tecnológico e de um bacharelado profissional geralmente se dá nas Seções de técnico superior (curso profissional em dois anos, que acontecem nos liceus).

${ }^{6}$ Pierre Bourdieu, Jean-Claude Passeron, Les héritiers, Paris, Minuit, 1964.
} 
que eles não herdaram de seus pais ao contrário de seus colegas mais favorecidos socialmente. Parece, assim, que o fracasso no primeiro ciclo universitário não tem apenas bases escolares (domínio dos saberes fundamentais), mas implica igualmente, e por vezes essencialmente, desajustamentos de ordem propriamente social (comportamento inoportuno, atitude deslocada, etc.) que podem provocar humilhações diversas e, finalmente, uma estigmatização da parte dos atores da orientação escolar, dos professores e dos outros estudantes. Este artigo apoia-se numa pesquisa quantitativa e qualitativa sobre os primeiros ciclos da Graduação $^{7}$ de uma universidade francesa de porte médio.

\section{Alunos que não estão no seu lugar}

A continuidade dos estudos no ensino superior dos bacharéis tecnólogos ou profissionais nada tem de evidente na França ${ }^{8}$. Ela parece ser atribuída a esses últimos como um favor, como se o simples fato de querer prolongar seu percurso escolar questionando assim o caráter conclusivo de seu diploma já fosse considerado como uma maneira de não jogar verdadeiramente o jogo. Em consequência, sua autorização para acessar ao ensino superior deve ser acompanhada de garantias e de justificações, e sobretudo restringir-se às áreas que Ihes foram concedidas. E, no centro do ensino superior, a Universidade constitui um espaço mui particularmente consagrado, ao qual eles não podem verdadeiramente pretender, segundo os atores da orientação escolar e os professores dos liceus e das faculdades. Para esses estudantes, cujo título de ingresso na Universidade não é considerado como legítimo, as observações repetidas de professores podem ter como efeito o desencorajamento dos requerentes.

\footnotetext{
7 Do original "Licence", que equivale grosso modo à graduação no Brasil, entretanto com duração de três anos. (N.T.)

${ }^{8}$ Em favor da segunda democratização escolar dos anos 1980-1990, as taxas de continuidade de estudos ao término desses dois diplomas aumentaram: elas abrangiam, em 2012, 76,4\% dos titulares de um bacharelado tecnológico e $28,7 \%$ dos titulares de um bacharelado profissional. Mas essas taxas permanecem distantes da taxa de continuidade de estudos no ensino superior no término de um bacharelado geral: $98,3 \%$.
} 
Os bacharéis tecnólogos e profissionais que, apesar de tudo, penetram na graduação universitária têm frequentemente plena consciência de que sua presença é considerada como ilegítima. Do liceu aos bancos da faculdade, eles estão convencidos, nos dois sentidos do termo (eles acreditam e são reconhecidos culpados), por não estarem no seu lugar. Um estudante do segundo ano de graduação em sociologia, oriundo de um bacharelado tecnológico, evoca nestes termos seu percurso:

Antes mesmo de obter nosso bacharelado, a direção do liceu nos entregou uma lista com todas as orientações que se podia receber. $O$ liceu chegou até mesmo a organizar uma espécie de assembleia que reagrupava todas as seções de técnico superior do liceu. Pois, sim, esse liceu comporta não somente um colégio, um liceu, mas também seções de técnico superior. Oferecendo, entre outros: Contabilidade, Métiers da moda, Secretariado, Comunicação Empresarial... O que me interessou foi Comunicação Empresarial, pois o mundo da publicidade me interessa muito, eu tenho com frequência ideias originais para vender tal ou tal produto, então para mim era uma formalidade apresentar minha candidatura para esse curso. Então eu me informei com os alunos representantes desta área, seu discurso não me pareceu muito convincente: "Todos os anos há 24 alunos admitidos dentre 400 inscrições", o que claro me desanimou, sabendo que eu não tenho um histórico escolar muito bom. Eles me aconselharam a fazer um ano de faculdade antes, pois foi isso o que eles fizeram, isso sempre pesa um pouco no histórico... um bom CV escolar. Meus professores faziam tudo para nos empurrar para as seções de técnico superior do liceu. Meu professor regente chegou a me dizer, nas entrelinhas, que se eu quisesse cursar a seção de Comunicação Empresarial, ele podia fazer algo por mim. Por outro lado, para eles, era impensável que se pudesse vislumbrar uma orientação para uma universidade, "a faculdade não está adaptada aos [bacharéis tecnólogos]"; "Vocês vão perder um ano"; como se nós fôssemos "subalunos", não suficientemente inteligentes. Isso foi sem dúvida o que mais me impulsionou a fazer uma faculdade, para provar a eles que se pode ter êxito na faculdade sendo proveniente de uma área tecnológica! Disso eu tenho certo ‘orgulho’.

(Estudante, Graduação 2 em sociologia, bacharelado em ciências $e$ tecnologias do terciário, pai: vendedor de peças de carro; mãe: secretária de consultório médico.)

Uma estudante do primeiro ano de Letras modernas, titular de um bacharelado tecnológico, conclui assim: "a formação não está adequada ao meu perfil. Além disso, por não ter vindo de um bacharelado literário [geral], muitos professores não deixam de me 
lembrar disso toda vez que podem." Os sinais implícitos ou explícitos da distância em relação a um perfil estudantil esperado podem portanto estar na origem de desencorajamentos e de abandonos. Uma estudante que abandonou seus estudos de línguas na Universidade explica que os alunos que não são titulares de um bacharelado geral são considerados em situação irregular: "Todo o mundo me dizia que, como eu não fiz um bacharelado Literário, eu não tinha nada que fazer na [graduação de] Letras Estrangeiras Aplicadas. Isso foi me dito uma vez, duas vezes, três vezes, e então eu acreditei. [...] Daí eu parei, trabalhei e retomei meus estudos."

O acesso ao ensino superior dos bacharéis tecnólogos e profissionais é portanto objeto de uma designação a certas formações privilegiadas e de uma manutenção à distância das formações universitárias. Esta gestão dos fluxos encontra em primeiro lugar sua justificativa na antecipação da inadaptação escolar desses estudantes às expectativas da Universidade.

\section{A defasagem escolar}

Esses estudantes experimentam, na verdade, em maior proporção do que seus colegas oriundos dos bacharelados gerais, dificuldades no primeiro ano da Universidade. Assim, $87 \%$ dos bacharéis profissionais e $83 \%$ dos bacharéis tecnólogos pensam que o nível no primeiro ano de graduação é superior ao do último ano do ensino médio ${ }^{9}$, contra $64 \%$ dos bacharéis gerais ${ }^{10}$. Comparativamente, nas STS $^{11}$, apenas $50 \%$ dos bacharéis profissionais consideram o nível do último ano do ensino médio superior, 32\% para os bacharéis tecnólogos e 13\% para os bacharéis gerais. Em compensação, são os bacharéis profissionais das Seções de técnico superior que percebem expectativas mais elevadas dos professores (76\%), em comparação com os de graduação 1 (69\%). Em maior proporção são igualmente os bacharéis tecnólogos e profissionais que se sentem desestabilizados pelas aulas em anfiteatro (respectivamente $28,5 \%$ e $26 \%$, contra $20,1 \%$

\footnotetext{
${ }^{9}$ Este é o ano em que se prepara para o bacharelado, que permite ingressar no ensino superior. Para uma visão detalhada do sistema de ensino francês, ver o esquema do Anexo 1.

${ }^{10}$ Fonte: SEEP, Universidade de Poitiers.

${ }^{11}$ Seções de técnico superior.
} 
para os bacharéis gerais). Eles também citam mais a palavra "dificuldades" para definir seu início de ano universitário (respectivamente 11,8\% e 13,3\%, contra 5,8\% para os bacharéis gerais). Uma enquete realizada somente junto aos estudantes da faculdade de Ciências Humanas e Artes assinala que eles encontram mais problemas na tomada de notas, e que, diferentemente dos bacharéis gerais, eles preferem trabalhar mais em grupo que sozinhos.

Sua maior distância com o ambiente universitário se ouve igualmente do lado dos professores que deploram estudantes imaturos, que não sabem mais nem ler nem escrever. Mas esses "grandes ares da decadência" ${ }^{12}$ não são novos. Cronicamente, os "novos estudantes"13 são acusados de não serem mais o que foram. Nos anos 1970, o novo público das universidades já era julgado “menos brilhante, lento”, apresentando "dificuldades no manejo da língua, sobretudo na escrita"14.

Mas para compreender as dificuldades dos estudantes dos bacharelados não gerais face à cultura escrita, à lógica da análise, é preciso lembrar a atrofia das disciplinas acadêmicas nos cursos tecnológicos e profissionais do ensino secundário ${ }^{15}$. Uma estudante, do primeiro ano de psicologia, titular de um bacharelado tecnológico, constata que os bacharéis científicos já aprenderam alguns conteúdos de algumas matérias: "para a fisiologia ou outras matérias, os bacharéis científicos têm muitas vantagens. Já, desde a primeira aula são coisas que eles já viram. Mas enquanto é preciso que se aprendam coisas que nunca se ouviu falar, de uma hora para a outra, os outros já conhecem esses termos, isso não é muito fácil."

Além disso, esses estudantes de primeira geração são confrontados com a "pedagogia implícita" da Universidade, que não coloca os estudantes em situação de

\footnotetext{
${ }^{12}$ Emmanuel Fraisse, “L'université au miroir de la lecture”, Esprit, n 8-9, 1993, p. 128-142.

${ }^{13}$ Valérie Erlich, Les nouveaux étudiants. Un groupe social en mutation, Paris, Fayard, 1998.

${ }^{14}$ Elementos evocados nas respostas para uma enquete realizada em 1977-1978 com atores universitários e sobretudo para a seguinte questão: "Há quinze anos, muitos estudantes de origem popular (bacharéis e não bacharéis) ingressam na Universidade. Eles têm, na sua opinião, um comportamento específico, motivações particulares, diferentes dos outros estudantes?", in Esprit, n 11-12, p. 197-215.

${ }^{15}$ Mais do que afirmar que "eles não são feitos para a faculdade", naturalizando assim implicitamente seu desajustamento, é mais correto dizer que "eles não são preparados para a faculdade", o que lembra que essa defasagem não é inata, mas o produto de uma construção.

${ }^{16}$ Pierre Bourdieu, Jean-Claude Passeron, Les héritiers, Paris, Minuit, 1964.
} 
igualdade. Na verdade, a própria especificidade do ensino na graduação universitária consiste em repousar sobre certas expectativas escolares que nunca são prescritas, nem mesmo enunciadas: as modalidades da tomada de notas em aula, as leituras complementares, as releituras de aula, etc. Um estudante titular de um bacharelado profissional no primeiro ano do IUT $^{17}$ Redes e Telecomunicações - pertencendo, entretanto, às áreas mais enquadradas da Universidade - revela dificuldades para compreender o que esperam os professores, para decifrar os títulos, para entender os sujeitos, dos quais ele deplora o caráter sibilino. Ele tem, aliás, a intuição de um funcionamento universitário não explícito, não formalizado, que precisa ser adivinhado permanentemente: "Eu tenho a impressão de que se a gente não fala todos os dias com os professores, eles não dão as informações importantes."

\section{A defasagem social}

Mas os julgamentos professorais não visam unicamente práticas propriamente escolares, eles designam igualmente todo um conjunto de comportamentos e de atitudes, de maneiras de ser em classe e fora dela que remetem a uma herança cultural específica. Aquele que entra num anfiteatro hoje pode ficar surpreso com o barulho do fundo vindo das discussões ininterruptas quando o professor entra, pode se admirar com as risadas e as gargalhadas dos estudantes que ocupam as últimas filas, pode se irritar com as telas dos notebooks conectados nas redes sociais mais do que no plano de aula, pode se incomodar ao ver mãos mais hábeis para enviar SMS do que para tomar nota. Mas essas crônicas de desordens universitárias são antigas. Nos anos 1970, já se observavam as mesmas atitudes nos estudantes, que saíam para buscar um sanduíche ou um café, as mesmas distrações - menos tecnológicas, certamente - ao folhear uma revista de cinema, os mesmos barulhos no fundo do anfiteatro ${ }^{18}$.

\footnotetext{
${ }^{17}$ Instituto Universitário de Technologia.

${ }^{18}$ Jean-Pierre Richardot, “Une semaine à Tolbiac”, Le Monde de l'éducation, mai 1977.
} 
Atrás dos problemas de aparência estritamente escolar - o fracasso no primeiro ano, o nível de conhecimento dos estudantes -, são na realidade categorias sociais que são visadas. A chegada desses novos públicos coloca, na verdade, em dúvida as normas dominantes de uso e de prática da Universidade. O que está em questão é, portanto, uma forma de "apropriação herética" ${ }^{19}$ da Universidade, que revela, claramente, com o jogo universitário, herdeiros. Mas esse questionamento dos novos públicos de estudantes e de suas práticas inapropriadas, que leva rapidamente a considerar os estudantes como mal intencionados, ignora situações vividas às vezes dolorosamente pelos estudantes. Seu caráter de novato tanto pode levá-los a ousar interpelar espontânea e regularmente os professores, o que é interpretado como insolência, quanto encerrá-los num silêncio que pode passar por desinteresse. Na verdade, a dificuldade para responder às expectativas professorais, para se adaptar à tomada de notas ou ainda para compreender as aulas e as leituras, pode produzir formas de exclusão ou de contestação. A ausência nos exames ou as formas de fugir das tarefas que devem ser entregues devem, portanto, ser analisadas como maneiras de livrar a cara mais do que como formas de correr o risco do fracasso ou da humilhação.

\section{Alunos a contratempo}

A desigualdade diante dos estudantes é redobrada por uma desigualdade "ao lado" dos estudos. O tempo não organizado, não controlado da "vida estudantil" faz tanto - senão mais - a diferença quanto o tempo dedicado às aulas. Em primeiro lugar, porque ele apela a maneiras de trabalhar e a modos de gerenciar seu tempo muito diferentes daqueles mobilizados nos liceus tecnológicos e profissionais.

Uma bacharel tecnóloga, admitida no IUT Técnicas de Comercialização, constata uma diferença de adaptação dos estudantes no universo tranquilo do sistema

\footnotetext{
${ }^{19}$ Utilizamos a expressão de Claude Poliak. Cf. Claude Poliak, La vocation d'autodidacte, Paris, L'Harmattan, 1992, p. 10.
} 
universitário, no seu "tempo elástico" "20: "Isso nos caiu um pouco em cima de certo modo. Enquanto isso existia, eles já sabiam. [Eles diziam]: “é isso, é preciso lidar com isso do jeito que é"."

Ela atribui a causa do desajustamento que enfrentou à sua origem escolar:

Penso que o fato de sair do liceu com esse tipo de bacharelado, talvez isso não corresponda muito ao IUT, não sei. No nível do ensino, a gente talvez esteja menos preparada do que, por exemplo, um bacharel geral, não sei. Penso que num bacharelado geral, eles preparam mais para um sistema como esse: IUT, faculdade. Penso que eles preparam mais do que nós.

(Estudante, $2^{\circ}$ ano de STS ${ }^{21}$ Assistente de Gerente - reorientação após um $1^{\circ}$ ano de IUT GEA, bacharelado em ciências e tecnologias da gestão, pai: operário não qualificado; mãe: controladora de qualidade numa gráfica)

Esta estudante exprime o sentimento de não ter sido preparada para o modo de organização exigido pelo sistema universitário, mesmo em sua forma mais organizada, o IUT. Mas, sobretudo, ela se dá conta de que outros estudantes, vindos das áreas gerais do secundário, herdaram (social e escolarmente) disposições para a gestão de um tempo descontínuo. No final do primeiro ano, apesar da autorização para passar à classe superior, esta estudante interrompe o IUT e entra na STS Assistente de Gerente, proposta no liceu em que fez o seu bacharelado.

A diferença se dá também no nível da "cultura livre", ou seja, de todas essas práticas extrauniversitárias que vêm nutrir, sem nada dizer, o trabalho universitário, e particularmente a capacidade para empregar seu tempo livre com discernimento, de maneira proveitosa para os estudos (para se cultivar, para se envolver numa associação, etc.). Aqueles que pensam que somente a assiduidade e a conformidade com o tempo de curso contam se enganam. Eles são implicitamente muito mais julgados pela comunidade universitária, pelo que fazem no e do seu tempo livre, assim como já haviam mostrado

\footnotetext{
${ }^{20}$ Stéphane Beaud, “Un temps élastique. Etudiants des 'cités' et examens universitaires”, Terrain, 1997, n 29, p. 43-58.

${ }^{21}$ Seção de Técnico Superior.
} 
Pierre Bourdieu e Jean-Claude Passeron em Os herdeiros ${ }^{22}$. Esse uso adequado do tempo extrauniversitário é socialmente situado: as categorias abastadas o empregam em lugares reservados ou privados, enquanto as categorias modestas o empregam mais no espaço público, à vista e sob o julgamento de todo o mundo.

Enfim, comportamentos que outrora estavam plenamente associados à vida estudantil são doravante estigmatizados e mesmo fortemente punidos ${ }^{23}$. A boemia estudantil dos anos 1960, que deixava o estudante "livre para ir passear ao invés de ouvir o professor" ${ }^{24}$, se transformou em absenteísmo estudantil. A multiplicação das formas de enquadramento da juventude estudantil (assiduidade obrigatória em TD ${ }^{25}$, etc.) inventou de fato novas formas de desvio. Passando de herdeiros a bolsistas, os estudantes diletantes se tornaram estudantes vadios. Sobre isso confirmam os relatórios recentes referentes à vida estudantil encomendados pelo Ministério do Ensino Superior e da Pesquisa, e que versavam respectivamente sobre a cola, o abandono e o álcool ${ }^{26}$ no ensino superior. Um certo número de estigmas morais, como o do dissimulador e do aproveitador, pensam sobre esses "novos estudantes" que desafiaram as fronteiras da Universidade, assim como pesam de modo geral sobre os migrantes ${ }^{27}$. Esses estudantes são suspeitos de querer passar um bom tempo a expensas da sociedade (sobretudo recebendo bolsas), quando não são simplesmente suspeitos de querer enganar a instituição buscando obter seu diploma pela fraude ou pelo recurso jurídico ${ }^{28}$. Enfim, esses estudantes que desafiam o tempo e o espaço universitário incomodam ${ }^{29}$. Eles provocam desordem na instituição pela sua presença não conforme, assim como por sua ausência. Eles são facilmente qualificados ou suspeitos de ser absenteístas ou

\footnotetext{
${ }^{22}$ Pierre Bourdieu, Jean-Claude Passeron, Les héritiers, Paris, Minuit, 1964.

${ }^{23}$ Para considerações similares sobre o ensino secundário, ver: Etienne Douat, L'école buissonnière, Paris, La dispute, 2011.

${ }^{24}$ Bertrand Girod de l'Ain, "Rentrée universitaire: l'augmentation du nombre des enseignants réduira-t-elle la proportion des échecs aux examens", Le Monde, 6 octobre 1959.

25 Trabalhos dirigidos. (N.T.)

${ }^{26}$ 2012: "La fraude aux examens dans l'enseignement supérieur". 2011: rapport Demuynck, "Le décrochage à l'Université". 2011: rapport Daoust, "Soirées étudiantes et week-ends d'intégration".

${ }^{27}$ Nicolas Fischer, "Protéger les mineurs, contrôler les migrants", Revue française de sociologie, vol. 53, 2012, p. 689-717.

${ }_{28}$ Jacques Coenen-Huther, “Les sociologies et la crise de l'Université: peur, aveuglement ou complicité?", Revue européenne des sciences sociales, Tome 38, $n^{\circ} 119,2000$, p. 89-102.

29 Étienne Douat, "La construction de l'absentéisme scolaire comme problème de sécurité intérieure dans la France des années 1990-2000", Déviance et Société, n 31, 2007, p. 149-171.
} 
fraudulentos em potência. Penalizados por não serem herdeiros, esses novos estudantes não podem gozar dos privilégios dos privilegiados.

\section{Táticas de adaptação}

O retorno às entrevistas sobre os primeiros passos na Universidade desses estudantes que não herdaram os códigos faz aparecerem todas as apropriações desajeitadas, tímidas, práticas, lugares e temporalidades. Essas considerações mostram, sobretudo, que o que se apresenta primeiramente como uma forma de contestação do jogo universitário e de suas normas se revela na verdade e com frequência como táticas e astúcias para se apropriar dessas normas e assim poder jogar esse jogo. Longe de manifestarem a expressão de uma rejeição, essas práticas e comportamentos não conformes são ao contrário o testemunho de uma verdadeira aculturação. O retrato de Loïc, estudante do $3^{\circ}$ ano de graduação em história, oriundo de um bacharelado profissional em Manutenção Audiovisual, é a esse respeito particularmente esclarecedor. Vê-se aqui de passagem o quanto a informação sobre os serviços oferecidos pela Universidade é insuficiente para a sua apropriação e o seu uso pelos estudantes. A pedagogia nem sempre é suficiente diante de certas barreiras sociais e simbólicas. 0 medo da ignorância pode por si só constituir um forte obstáculo à integração universitária. O medo de fazer errado ou de ser ilegítimo leva Loïc a frequentar a biblioteca universitária apenas bem tarde. Não que ele não tenha interesse em consultar livros para seu trabalho, mas sobretudo porque ele não dominava os códigos. Seu silêncio e sua solenidade o incomodam. A perspectiva de se fazer notar, de parecer ridículo ao menor barulho, atraindo todos os olhares para si, o paralisa. Por isso, ele prefere a midiateca, cuja animação o protege dos erros de uso. Além disso, ele descobre também muito tarde a existência de outros livros além daqueles presentes nas seções. Essas formas de evidência e de familiaridade para aquele que frequenta as bibliotecas desde sua infância constituem surpresas, descobertas para outros. Não somente os novatos devem reduzir a distância que os separa dos saberes e das aprendizagens universitárias, 
mas eles ainda têm, para fazê-lo, que decodificar o funcionamento de certo número de lugares e de práticas cujos modos de emprego permanecem fortemente implícitos. Do lado oposto deste duplo sofrimento que acomete os bacharéis tecnólogos e profissionais, os bacharéis gerais se aproveitam com frequência do delito de iniciados.

- E então, para trabalhar, por exemplo, a descoberta da BU? Foi...

[Ele ri]... Tardia! A biblioteca de história da faculdade, lá eu ia de vez em quando... Era o mais simples. $\mathrm{Na} \mathrm{BU}$ eu tive que ir somente a partir do segundo semestre do $1^{\circ}$ ano. Não gosto daquele lugar... É um lugar frio [reforça a palavra], tu entras, tem a impressão de entrar numa igreja, todo mundo te olha... Enfim, é isso, tu não ficas totalmente à vontade. Se tu mexes tua cadeira ressoa por toda a sala. Enfim, bom. Não é tão viva quanto à midiateca.

- Então tu, tu ias à midiateca e à biblioteca setorial. Com que frequência?

Eu ia lá..., na época, ia todos os dias. Todos os dias. E na midiateca todos os finais de semana e todas as quartas-feiras.

- Tu trabalhavas lá?

Sim, sim, sim. Eu não trabalho em casa. Impossível trabalhar em casa. Aliás, ainda hoje, tenho dificuldade. É preciso que eu vá para outro lugar. $\mathrm{E}$ até mesmo para um bar, se for preciso, quando as midiatecas estão fechadas.

- Tu não consegues se empenhar sozinho?

Ah sim, não! Há a tela do computador lá, tu és tentado a ligar e depois não faço mais nada. Eu sei. Mas bom, agora, me habituei. Tenho meu método de trabalho. Eu me impeço... isso não me exige um esforço considerável. Só é preciso que eu trabalhe fora, não posso ficar em casa.

- Tu emprestavas livros ou os comprava?

Levei muito tempo para ousar emprestar livros. Achava isso... não sei. Eu não ousava. Eu ficava consultando no local. Antes de compreender, ademais, que há livros que você podia consultar mas que não estavam nas estantes. Que tinha um depósito atrás. Então, acho, eu descobri [isso] no final do $1^{\circ}$ ano e utilizei somente a partir do $2^{\circ}$ ano. Levei tempo para entender o Sistema da biblioteca. Eu me adaptei. Tu imaginas? Eu não tinha mais ido a uma biblioteca desde o colégio. Na época em que tu és obrigado a ir à biblioteca, quando tu tens uma hora de permanência. Porque (ele suspira) bibliotecas havia, sim, claro, nos liceus 
profissionalizantes, mas... elas estavam empoeiradas! Tu ias mais rapidamente ao laboratório de informática.

O que aparece claramente na descrição feita por Loïc de sua familiarização progressiva com a disciplina é o medo de cometer gafes. Vimos isso em relação ao uso dos lugares e dos serviços da vida estudantil. Isso aparece igualmente na sua maneira de apreender o trabalho universitário. Para compensar a ilegitimidade do seu bacharelado e manter à distância o estigma de um título escolar inapropriado, ele recorre a astúcias e táticas para embaralhar as cartas. Convencido de sua ilegitimidade em relação aos outros estudantes, ele se virou para entregar seus trabalhos escritos durante todo o seu $1^{\circ}$ ano e postergar o maior tempo possível as apresentações orais:

Eu me virei muito bem até o $2^{\circ}$ ano, eu não me sentia pronto, naquele momento, para fazer uma apresentação diante da turma. Sabendo que se eu tivesse apresentado na primeira vez, eu seria... Isso teria sido um "fuzilamento". Porque seria uma porcaria. Eu teria apresentado alguma coisa que era [ele suspira]... Estava no limite. Quando releio hoje, eu rio. As primeiras [apresentações], eu me virava cada vez. Quando se trata de apresentações, tu sabes como isso é, é uma confusão. E eu, eu sempre entreguei por escrito, durante dois anos. Durante um ano! Durante um ano eu consegui me virar e entregar tudo por escrito [ele sorri], sem fazer apresentação.

E quando ele não conseguiu mais escapar, ele propôs um "método", como afirma, que permitiu valorizar suas qualidades (a presença cênica, pode-se dizer) e mascarar suas lacunas (a escrita): “eu me saí muito bem, e falando verdadeiramente de forma distinta, sem fazer muito barulho. Eu me distancio das minhas anotações: eu marco apenas uma ou outra palavra com pontos. Tento dar uns toques de humor. Eu olho com muita frequência para as pessoas." Na escrita, incapaz de se lembrar das datas, ele se diverte contentando-se com períodos históricos:

Eu conto em quarto de século. Não consigo me lembrar de uma data precisa. Quando tu colocas uma data precisa numa redação de história e se engana sobre a data, tu passas por bobo. Tu passas por imbecil diante do professor e, além disso, de passagem, isso confirma... Se tu dizes: "no 
primeiro quarto do século XX", tu sabes que é por volta de 1910 mais ou menos, tu sabes, tu não sabes muito... Primeiro quarto do século $X X$, segundo quarto do século XX... Tu falas assim, isso te permite se aproximar... Tu substituis sempre duas ou três datas-chaves que tu reténs. Mas enfim, essa é uma técnica que permite funcionar. E nesse aspecto, tudo bem. E, assim, eu não confundo meu espírito com as datas. Depois, eu sempre sei mais ou menos como se desenvolvem os acontecimentos. Grosso modo.

Essas defesas devem ser compreendidas como maneiras de livrar a cara, de evitar o erro que remeteria à suas origens escolares, e não como uma astúcia para enganar os professores. Esta atenção dada às suas práticas e a preocupação em desafiar as faltas de jeito não impedem, entretanto, os maus julgamentos. Assim, num setor disciplinar - as ciências sociais - no interior do qual a difusão da pesquisa passa amplamente pela publicação de artigos científicos, Loïc não os utiliza muito para fazer suas apresentações. Aqui também, posto em situação de fragilidade devido ao seu bacharelado, ele tem medo de não conseguir fazer o bastante e teme que a mobilização de artigos mais do que de livros passe por diletantismo. As hesitações que pontuam a sua justificativa são reveladoras do seu mal-estar:

Eu não sei. Não. Nunca... Não, porque em história há muitos livros para que se vá procurar nos artigos. De todo modo, sabe-se que o cara que fez um artigo fará um livro sobre o assunto. E frequentemente, já o fez. Enfim, a menos que seja muito, muito recente. Eu, eu nunca tive... enfim, eu não sei, pode ser ruim, hem... Não sei. Eu tenho a impressão de que frequentemente, isso dá, veja, algo de muito... enfim, é isso, é isso... Eu não sei, tenho dificuldade de utilizá-los. Não costumo utilizar artigos. Não criei o hábito e não os utilizo, não sei por quê. Eu sempre tive medo de que fosse muito... não o suficiente... que não seja denso o bastante, para fazer... para fazer uma apresentação, bem, é isso. Isso é idiota, hem.

No final, e apesar da grande distância inicial em relação às exigências universitárias, Loïc conseguiu levar a cabo os três anos de graduação, não sem ter que fazer em cada ano um semestre de recuperações. O que aparece claramente neste sucesso improvável é que todo o trabalho empreendido para evitar o estigma escolar ("passar por bobo" como ele diz) o obrigou a decifrar as expectativas universitárias. Com 
medo de dar um passo em falso, ele decodificou os implícitos da disciplina mas também os dos professores. Pois o métier de estudante é ao mesmo tempo a apropriação de uma matriz disciplinar ${ }^{30}$ e o ajuste às especificidades próprias de cada professor. Ele está doravante em condições de explicar que concentra suas revisões na história medieval tanto porque a disciplina "demanda muito trabalho" quanto porque "não se sabe que [os professores] são minuciosos".

\section{Conclusão}

Nos anos 1960 Pierre Bourdieu e Jean-Claude Passeron mostraram, por meio de Os herdeiros, como os estudantes se sentiam julgados e orientados no ensino superior, tanto, se não mais, em função de seu perfil social quanto de seu perfil propriamente escolar. As inúmeras transformações que modificaram fortemente desde então a paisagem do ensino superior francês - sobretudo sua massificação e sua diversificação poderiam levar a crer que as coisas mudaram muito. Não somente nosso trabalho mostra que não foi isso o que aconteceu, ao contrário, ele revela como o processo de exclusão social que age no seu interior sem dúvida ganhou em eficácia e em invisibilidade na medida em que a divisão recente em três tipos de bacharelados (cobrindo majoritariamente três perfis sociais de alunos) duplicou no ensino superior os antigos mecanismos que transvertem julgamentos sociais em julgamentos de aparência escolar.

\footnotetext{
${ }^{30}$ Mathias Millet, Les étudiants et le travail universitaire. Étude sociologique, Lyon, PUL, 2003.
} 
Anexo 1. Esquema simplificado do sistema de ensino na França

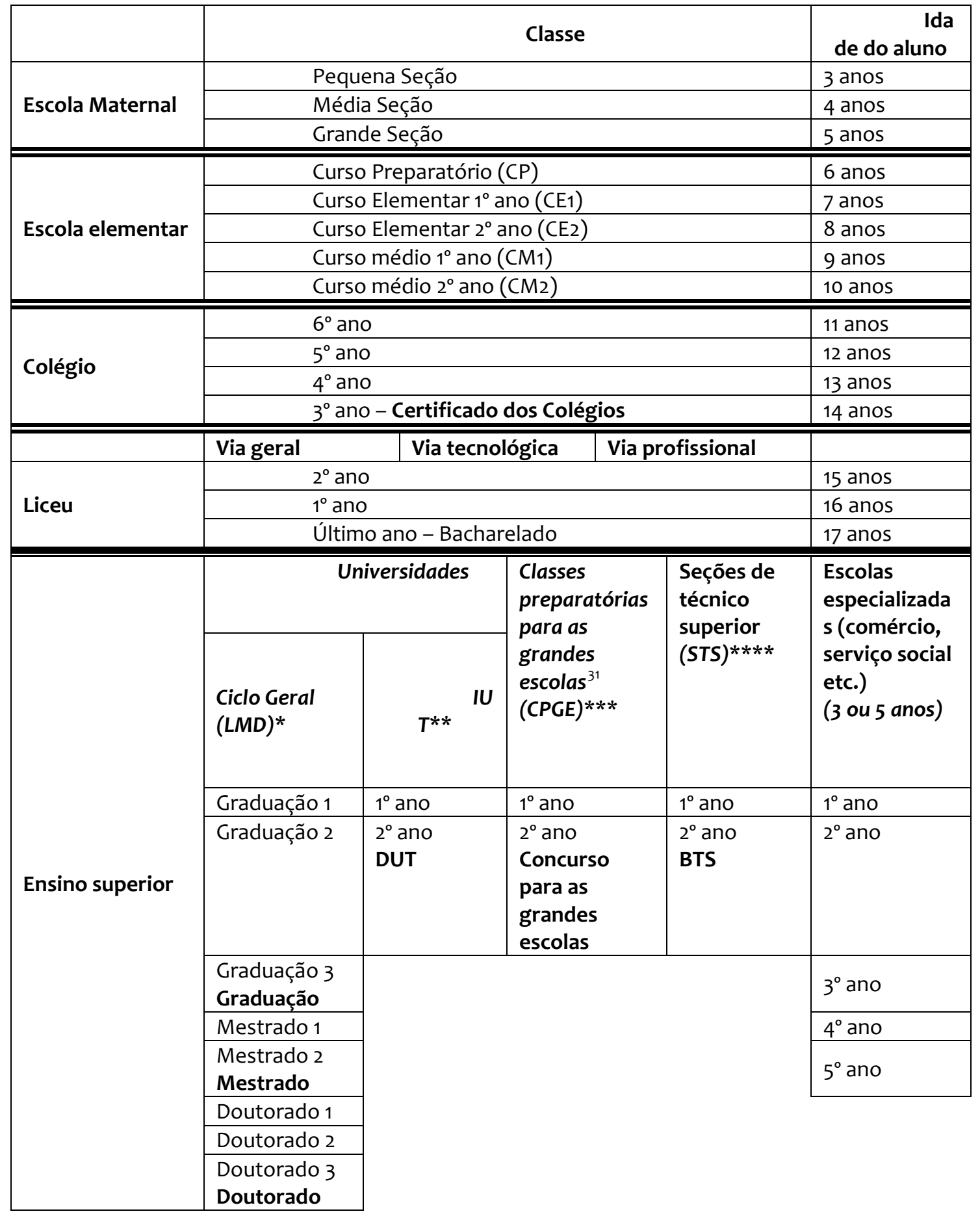

\footnotetext{
${ }^{31}$ As grandes escolas formam os futuros dirigentes principalmente nas áreas tecnológicas e administrativas, propondo-lhes um ensino múltiplo ou específico (com a duração de no mínimo cinco anos após o liceu) reconhecido pelo Estado e assegurando-lhes as melhores oportunidades de acesso aos cargos públicos e empresariais de maior prestígio. (N.T.)
} 
* A Universidade francesa está dividida em cursos disciplinares que conferem diplomas de graduação, de mestrado e de doutorado. Por exemplo: graduação em sociologia, mestrado em sociologia, doutorado em sociologia, graduação em matemática, mestrado em matemática, doutorado em matemática, etc.

** IUT: Instituto Universitário de Tecnologia: curso oferecido pela Universidade, cujo acesso se faz por meio de uma seleção. Nele é ministrado um ensino geral e tecnológico a grupos menores que os da graduação universitária. Após dois anos de formação, o estudante obtém um diploma universitário de tecnologia (Diplôme universitaire de technologie - DUT).

*** As classes preparatórias para as grandes escolas são cursos situados em liceu de ensino secundário, cujo acesso se faz por meio de uma seleção. Estes cursos preparam para as grandes escolas. Eles abrigam cursos de elite.

**** As seções de técnico superior estão situadas nos liceus de ensino secundário, cujo acesso se faz por meio de uma seleção. Nelas é oferecido um ensino tecnológico e profissional. No final dos dois anos de formação, o estudante obtém um certificado de técnico superior (Brevet de technicien supérieur - BTS).

\section{Referências}

BEAUD, Stéphane. “Un temps élastique. Etudiants des 'cités' et examens universitaires”. Terrain, 1997, $\mathrm{n}^{\circ}$ 29, p. 43-58.

BOURDIEU, Pierre et PASSERON, Jean-Claude. Les héritiers. Paris, Minuit, 1964.

COENEN-HUTHER, Jacques. “Les sociologies et la crise de l'Université: peur, aveuglement ou complicité?”. Revue européenne des sciences sociales. Tome 38, n 119, 2000, p. 89-102.

DAOUST, Martine (Recteur de l'académie de Poitiers). Rapport du groupe de travail sur la mission «soirées étudiantes et week-ends d'intégration». 2011. Disponível em http://www.upsud.fr/_attachments/fsdie2/Rapport_Daoust.pdf?download=true ${ }^{32}$.

DOUAT, Étienne. “La construction de l'absentéisme scolaire comme problème de sécurité intérieure dans la France des années 1990-2000”. Déviance et Société, n³1, 2007, p. 149171.

DOUAT, Etienne. L'école buissonnière. Paris, La dispute, 2011.

ERLICH, Valérie. Les nouveaux étudiants. Un groupe social en mutation. Paris, Fayard, 1998.

FISCHER, Nicolas. "Protéger les mineurs, contrôler les migrants". Revue française de Sociologie. vol. 53, 2012, p. 689-717.

FRAISSE, Emmanuel. “L'université au miroir de la lecture”. Esprit, n 8-9, 1993, p. 128-142.

\footnotetext{
${ }^{32}$ NT. Acesso em 30 de setembro de 2014.
} 
FRANCE. Ministere De L'éducation Nationale, De L'enseignement Superieur Et De La Recherche. Remise du rapport Demuynck, “Le décrochage à l'Université", 2011. Disponível em http://www.enseignementsup-recherche.gouv.fr/cid56550/remise-durapport-du-senateur-demuynck-sur-le-decrochage-a-l-universite.html. ${ }^{33}$

FRANCE. Ministere De L'education Nationale, De La Jeunesse Et De La Vie Associative Ministere De L'enseignement Superieur Et De La Recherche. Inspection générale de l'administration de l'éducation nationale et de la recherche. "La fraude aux examens dans l'enseignement supérieur", 2012. Disponível em http://cache.media.enseignementsuprecherche.gouv.fr/file/2012/94/1/2012-027_rapport_217941.pdf ${ }^{34}$.

GIROD DE L'AIN, Bertrand. “Rentrée universitaire: l'augmentation du nombre des enseignants réduira-t-elle la proportion des échecs aux examens", Le Monde, 6 octobre 1959.

MILLET, Mathias. Les étudiants et le travail universitaire. Étude sociologique, Lyon, PUL, 2003.

POLIAK, Claude. La vocation d'autodidacte. Paris, L'Harmattan, 1992.

RICHARDOT, Jean-Pierre. “Une semaine à Tolbiac”. Le Monde de l'éducation, mai 1977.

THIESSE, Anne-Marie. «Des plaisirs indus. Pratiques populaires de l'écriture et de la lecture». Politix, n 13,1991 , p. 57-67.

Recebido em: 10/09/2013

Aprovado em: 22/02/2014

Universidade do Estado de Santa Catarina - UDESC Programa de Pós-Graduação em Educação - PPGE

Revista Linhas

Volume 15 - Número 29 - Ano 2014 revistalinhas@gmail.com

\footnotetext{
${ }^{33}$ NT. Acesso em 30 de setembro de 2014.

${ }^{34}$ NT. Acesso em 30 de setembro de 2014.
} 